\title{
Removal of MnS inclusions in molten steel using electropulsing
}

\author{
X. F. Zhang*, W. J. Lu and R. S. Qin* \\ Department of Materials, Imperial College London, Exhibition Road, London SW7 2AZ, \\ United Kingdom
}

\begin{abstract}
A method using electropulsing to separate inclusions from molten steel is developed, based on the differences in electrical properties between the inclusions and liquid metal. The inclusions have different electrical resistivity from that of the liquid steel and hence being expelled to the surface of the metal by electropulsing. In comparison with the as-solidified untreated steel, the size of the inclusion is significantly larger at the surface of the molten steel due to the enhanced agglomeration. Moreover, the technique is efficient in eliminating particles smaller than $20 \mu \mathrm{m}$.
\end{abstract}

Keywords: Electropulsing; Inclusions; Electrical properties; Molten steel; Phase separation

*Corresponding authors. Tel. +44 207594 6803; Fax: +44 (0)20 7594 6757;

e-mail: xin-fang.zhang@imperial.ac.uk (X. F. Zhang); r.qin@imperial.ac.uk (R. S. Qin) 
The non-metallic inclusions usually have significantly different thermal and mechanical properties from those for the metal matrix. This leads to stresses, cracks, creep, microstructure instability and many other detrimental effects during thermomechanical processing and the service loading of steels [1-3]. The removal of inclusions to improve the cleanliness of the steels has been a continuous effort in both academia and industry. There are a number of clean steel fabrication techniques applied in large scale productions, e.g. electromagnetic stirring, bubbling and filtration [4-7]. However, these conventional methods are not efficient in eliminating particles whose sizes are smaller than $20 \mu \mathrm{m}$, and accompanied with significant energy consumption [4-7].

Electropulsing has been applied in many aspects of metal processing such as electroplasticity [8], microstructural refinement [9] and structural relaxation [10, 11]. Experiments have demonstrated significant effect of electropulsing on the microstructural evolution in metals, e.g., segregation of lead inclusions in $\mathrm{Cu}-\mathrm{Zn}$ alloy [12] and the fragmentation of the cementite plates in strained pearlitic steel [13]. The diffusive transformation can be accelerated due to the enhancement of the diffusivity by electropulsing [14]. There is to date no report on the application of electropulsing to affect the configuration of inclusions in molten steels. On the other hand, electropulsing processing consumes negligible amount of energy in comparison with other clean steel processing techniques such as electromagnetic stirring. This might help to reduce the energy consumption and energy-related green house gas emission once the principle of the electropulsing treatment is established.

$\mathrm{MnS}$ as a common inclusion adversely influences the mechanical properties, physical properties and corrosion resistance of the steels $[15,16]$. Thus, a steel that contained MnS 
particles was selected for the present study. The objective of this study was to evaluate the feasibility of the electropulse-driven inclusion removal from molten steel. This includes the quantitative characterization of the total amount of inclusions and the average size of inclusions in molten steel. In addition, this new method using electropulsing is based on the differences in electrical properties between inclusions and steels, not on the disparities in the density or size as employed by the conventional methods. This implies that, in principle, electropulse-based processing should work for inclusions of various sizes rather than those inclusions whose sizes are larger than $20 \mu \mathrm{m}$ only.

In this letter, a steel with the chemical composition (wt.\%) $0.74 \mathrm{C}, 0.27 \mathrm{Si}, 0.99 \mathrm{Mn}, 0.019 \mathrm{~S}$, $0.016 \mathrm{Cr}$ and $0.015 \mathrm{Ni}$ was used. The specimens were prepared in an induction furnace. The frequency of the heating current is $195.8 \mathrm{kHz}$. Prior to the heating, two electrodes made by magnesia carbon refractory containing 15 wt.\% carbon was positioned uprightly in the cylindrical graphite crucible. The steel was heated above its melting temperature, held at that temperature for 1 hour, then furnace cooled to room temperature. The samples were divided into two groups with each group containing two test pieces. Group 1 was processed without electropulsing. Group 2 was with exactly the same heat treatment as Group 1 but with the addition of electropulsing at the molten stage for 20 minutes. The total holding time for both groups of samples at the liquid state was the same. The frequency of electropulse is $1 \mathrm{~Hz}$. The duration of each electropulse is $20 \mu \mathrm{s}$. The density of the pulsed electric current is $1.2 \times 10^{5}$ $\mathrm{A} / \mathrm{m}^{2}$. The size of the ingot is $19 \mathrm{~mm}$ (longitudinal length) $\times 12 \mathrm{~mm}$ (width) $\times 15 \mathrm{~mm}$ (thickness). The longitudinal section was observed to detect the inclusions distribution. 
The cooled specimens were longitudinal sectioned, polished and etched by $4 \%$ Nital reagent for metallographic examination. The composition of the inclusions in the steels was analysed with scanning electron microscopy (SEM) equipped with energy dispersive spectroscopy (EDS).
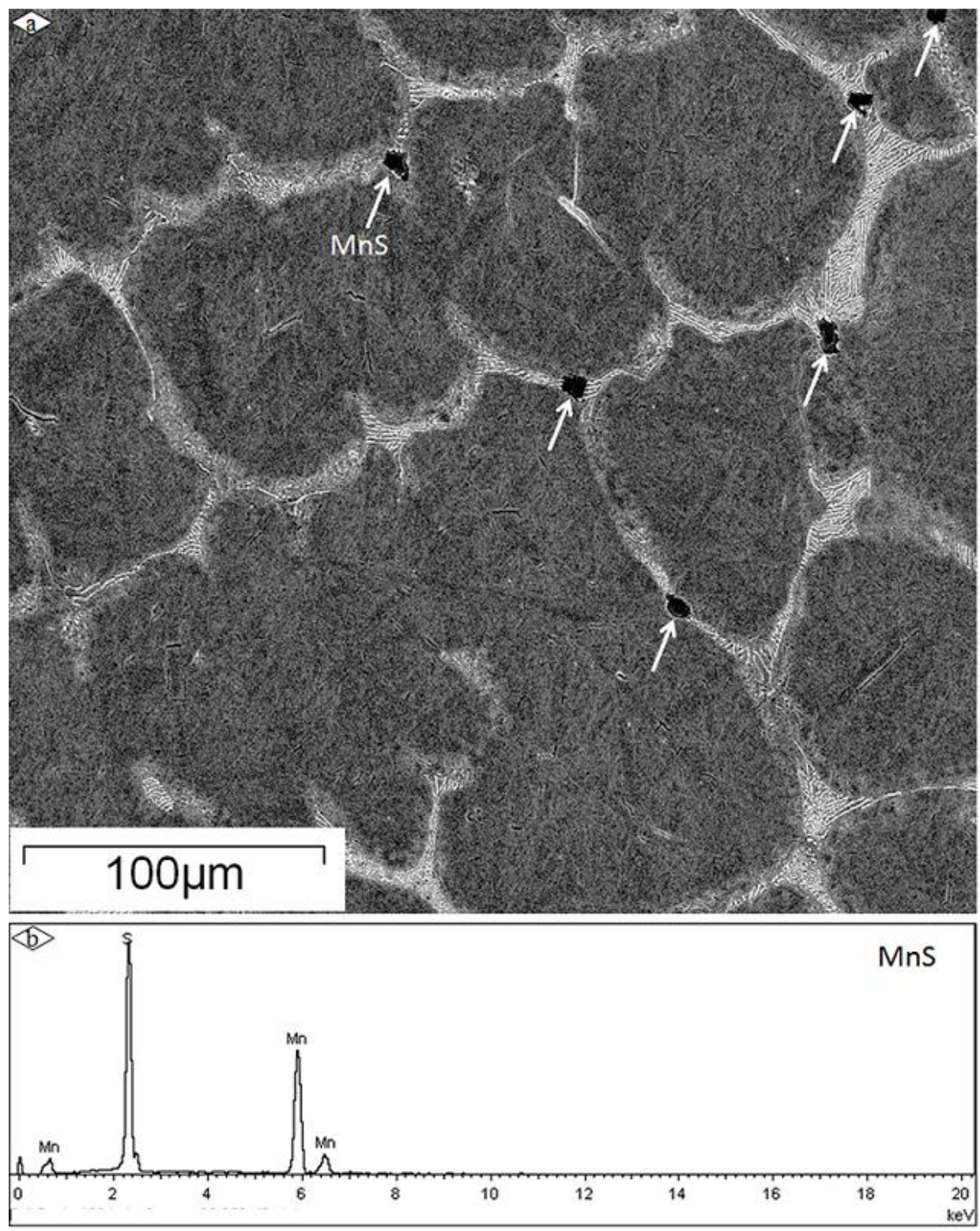

Figure 1 a) The dark phases marked by arrows are uniformly distributed at the as-solidified untreated steel. b) EDS analysis shows the dark phase is MnS inclusion. 
Figure 1a demonstrates the microstructure of the as-solidified untreated steel by SEM image. It can be seen that the dark phases marked by arrows was uniformly distributed in the steel matrix. The morphology was in the form of regular round or square. The diameter of the phases varied from $5 \mu \mathrm{m}$ to $15 \mu \mathrm{m}$. An EDS analysis for the sample shown in Figure 1a, as illustrated in Figure $1 b$, revealed that the dark phase was $\mathrm{MnS}$ inclusion. However, the distribution of the MnS inclusions was completely different in the electropulsed steel, as shown in Figure 2 and 3. Fig. 2(a) and 2(b) are obtained from the same sample but with different magnifications. It is obvious that the $\mathrm{MnS}$ inclusions disappeared from the inner part of the steel matrix, and instead they were dispersed as relatively large-sized $\mathrm{MnS}$ aggregates with irregular shape at the surface of the steel. Figure 3 shows the morphologies of the $\mathrm{MnS}$ inclusions after the electropulsing treatment. Fig. 3(a) and 3(b) are obtained from the same sample but with different magnifications. It does not present a regular round or square, but the form of long rods or short rods. The change in the rod length was ranging from $13 \mu \mathrm{m}$ to $35 \mu \mathrm{m}$. This means that the passing electric current enables to drive the $\mathrm{MnS}$ particles motion to the surface of the steel and achieve much larger size as a result of the aggregation.

Table 1 demonstrates the statistical results for the amount and average size of inclusions in the samples with and without the electropulsing treatments. For the sample without electropulsing treatment, there are 15 inclusions with an average size of $9 \mu \mathrm{m}$ distributed randomly in an area of $0.291 \mathrm{~mm}^{2}$. After electropulsing, however, no inclusions are found at the inner part of the matrix but 47 inclusions with average size of $18 \mu \mathrm{m}$ are found in an analysed area of $0.291 \mathrm{~mm}^{2}$. 


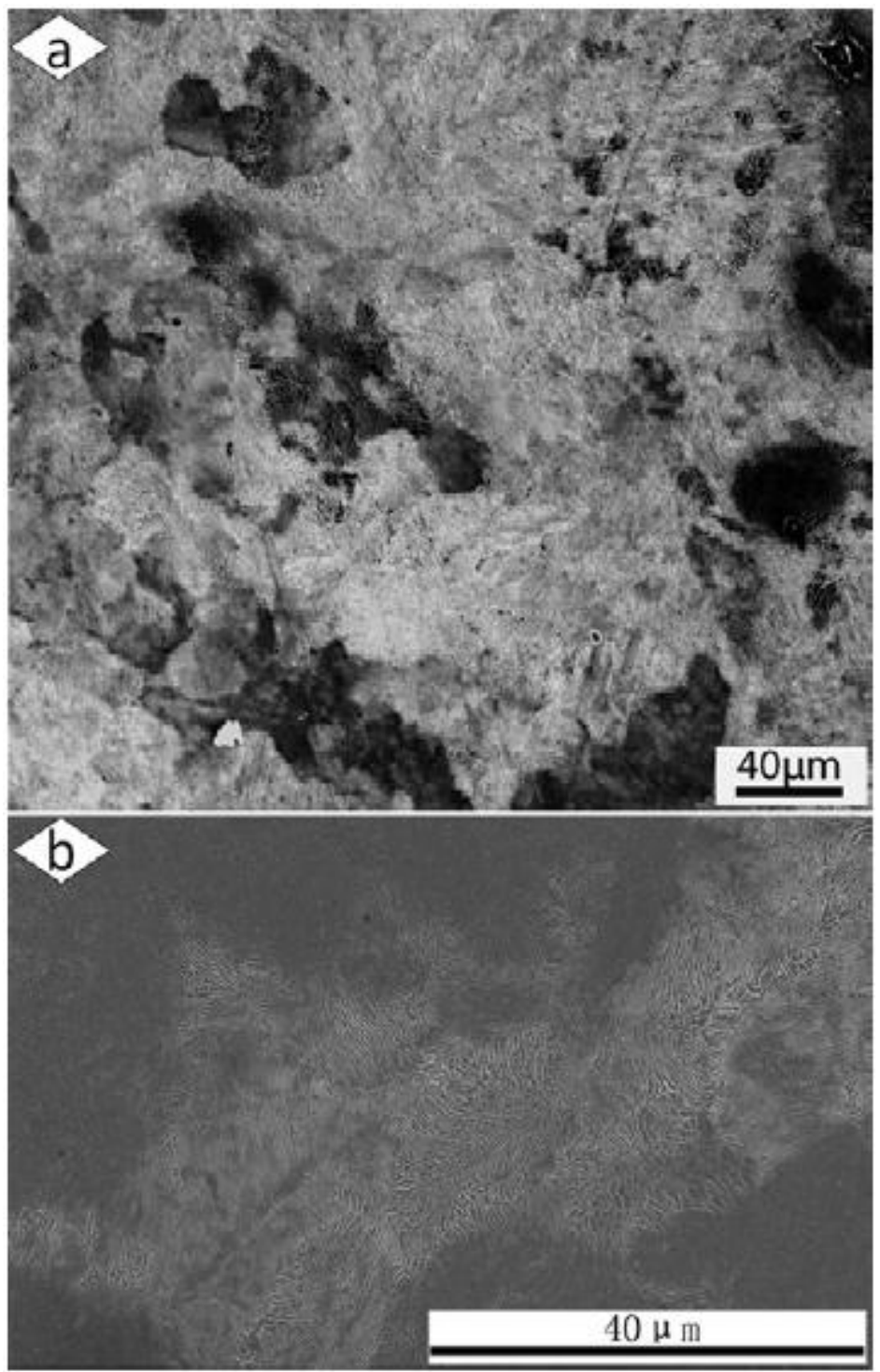

Figure 2 The MnS inclusions disappear from the inner part of the steel ingot after the electropulsing treatment, where (a) and (b) are from the same sample but with different magnifications. 


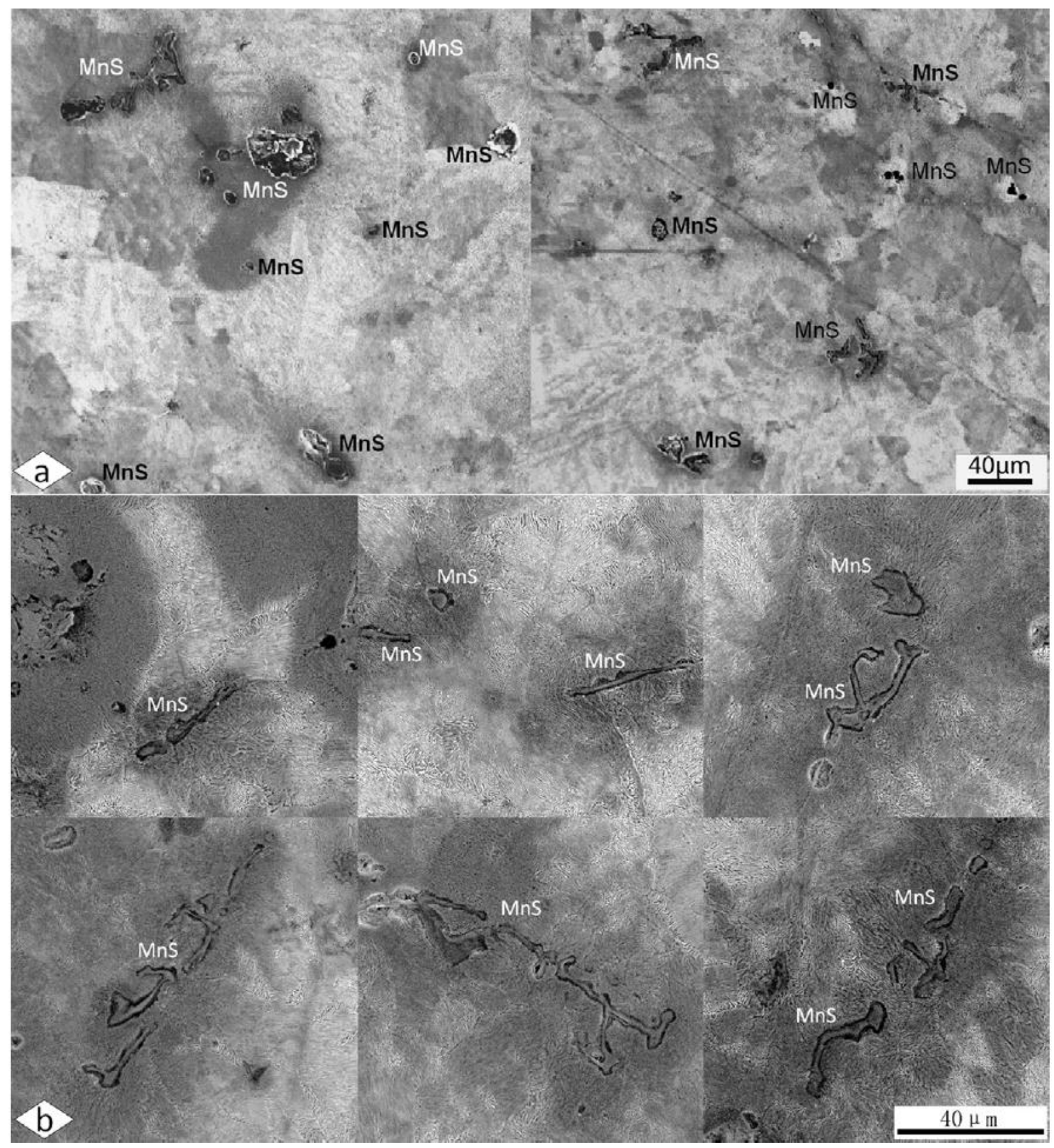

Figure 3 The MnS inclusions with large size are dispersed at the surface of the studied steel after the electropulsing treatment, where (a) and (b) are from the same sample but with different magnifications. 
Table 1 Quantitative characterization of the amount of inclusions and the average size of inclusions in molten steel before and after the electropulsing treatment.

\begin{tabular}{cccc}
\hline & Untreated steel & $\begin{array}{c}\text { Treated steel } \\
\text { (surface) }\end{array}$ & $\begin{array}{c}\text { Treated steel } \\
\text { (inner matrix) }\end{array}$ \\
\hline Number of fields & 3 & 3 & 3 \\
Field area $\left(\mathrm{mm}^{2}\right)$ & 0.097 & 0.097 & 0.097 \\
Analysed area $\left(\mathrm{mm}^{2}\right)$ & 0.291 & 0.291 & 0.291 \\
Number of inclusions & 15 & 47 & 0 \\
Range of & 5 to 15 & 13 to 35 & 0 \\
length/diameter $(\mu \mathrm{m})$ & 9 & 18 & \\
Average & & & 0 \\
length/diameter $(\mu \mathrm{m})$ & 9 & & \\
\end{tabular}

Before discussing the inclusions removal by electropulsing, electromagnetic stirring induced by the induction furnace must be clarified. Induction heating is the process of heating an electrically conducting metal by electromagnetic induction, where eddy currents are generated within the metal and resistance leads to Joule heating of the metal. Usually, the electromagnetic force exerted on the molten metal is inversely proportional to the square root of the frequency of the induced current, that is, lower frequencies (below $30 \mathrm{kHz}$ ) can generate stirring in the molten metal [4]. In this study, the frequency of the heating current at $195.8 \mathrm{kHz}$ is approximately 6.5 times larger than that of normal lower frequency at $30 \mathrm{kHz}$. Although the stirring is still presented in the high frequency magnetic field, its effect on the inclusion configuration is negligible. This can be demonstrated by the observed uniformly distributed inclusions in the as-solidified untreated steel (Figure 1). 
When an electric current passes through a conductor, the free energy $G_{e}$ associated with electric current, according to the previous studies $[12,13]$, is given by the following expression.

$$
G_{e}=-\frac{\mu}{8 \pi} \int \frac{\vec{j}(r) \cdot \vec{j}\left(r^{\prime}\right)}{\left|r-r^{\prime}\right|} d r d r^{\prime}
$$

where $\mu$ is the magnetic permeability, $r$ and $r^{\prime}$ are two different positions in space, respectively. $\vec{j}(r)$ is the current density at position $r$. The distribution of electric current density in steel is affected by the configuration of electrical conductivity in the materials. Inclusions have different electrical properties from that of the liquid steel. The different configuration of the inclusions results in different current density distribution. When an inclusion moves from the inside towards the surface of the liquid steel, the current density distribution will be changed from $\vec{j}_{1}(r)$ to $\vec{j}_{2}(r)$. The associated free energy change $\Delta G_{e}$ can be expressed as $[12,13]$

$$
\Delta G_{e}=\frac{\mu}{8 \pi} \iint \frac{\vec{j}_{1}(r) \vec{j}_{1}\left(r^{\prime}\right)-\vec{j}_{2}(r) \vec{j}_{2}\left(r^{\prime}\right)}{\left|r-r^{\prime}\right|} d^{3} r d^{3} r^{\prime}
$$

Quantitative calculation of $\Delta G_{e}$ had shown that the free energy difference plays an important role in nucleation [17], crystal growth [18], inclusion segregation [12], crack healing [11], phase transformation [19], and solidification [20]. The move of the inclusion from the inner liquid steel to the surface results in the reduction of the free energy associated with the electric current.

Figure 4 demonstrated schematically the interaction between the current and the non-metallic inclusion. The distribution of current with an inclusion inside the matrix is present in Figure 4a, while that with an inclusion close to the surface of the metal is displayed in Figure $4 \mathrm{~b}$. The current distribution in Figure $4 \mathrm{~b}$ is different from that in Figure 4a due to different location of the inclusion particle. Generally, the different configurations of $\mathrm{MnS}$ inclusions in liquid steel 
will affect the electrical current distribution in the whole system due to the significantly higher electrical resistivity of $\mathrm{MnS}$ compared with that for the molten steel. The different current distributions correspond to various system free energy. The electrical conductivity of the molten steel is equal to $10^{5} \Omega^{-1} \cdot \mathrm{m}^{-1}$ [21] and that of $\mathrm{MnS}$ above $1273 \mathrm{~K}$ is approximately $10^{2} \Omega^{-}$ ${ }^{1} \cdot \mathrm{m}^{-1}$ [22]. The value of the MnS inclusion is $10^{3}$ smaller than that of the molten steel. The current density inside the inclusion is lower than that of the outside. In order to minimize the system free energy, an inclusion will be expelled to the surface of the molten steel by electropulsing.
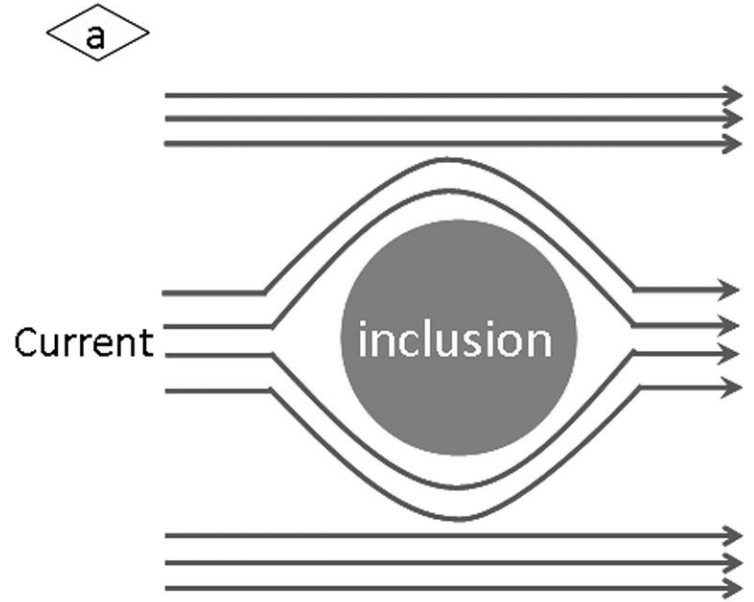

Liquid steel

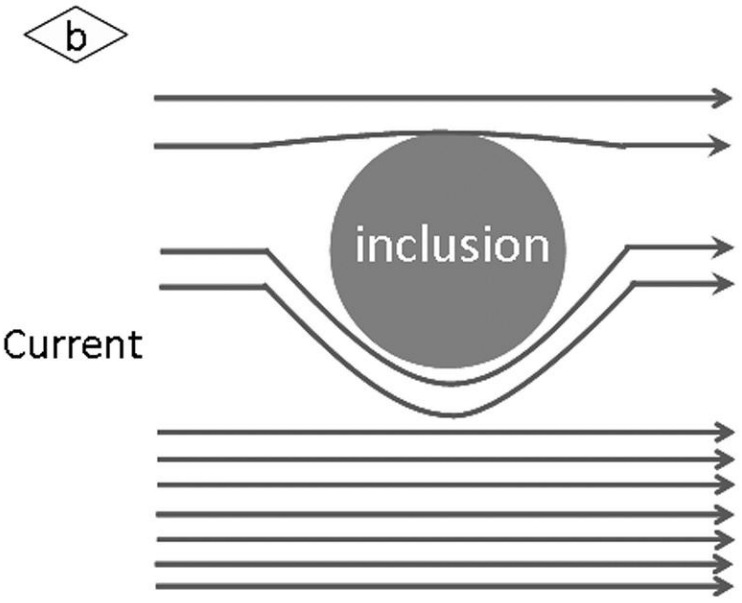

Liquid steel

Figure 4 Current line distributions during an electric current passing through liquid steel containing inclusions at different locations, a) an inclusion is inside the matrix, and b) an inclusion is close to the surface of the metal.

Such a phenomenon has not been noticed before because the existing calculations on the free energy associated with the passing of electric current is usually with assumption of an infinitely large matrix. In that case the different locations of an inclusion in the matrix do not make any differences to the total free energy. The size of the liquid steel in the present study cannot be treated as infinite when compared with the size of the inclusions, especially when the 
inclusion is close to the surface of the liquid steel. The effect is therefore become significant. In the ideal state, e.g., the reference state for Equation 1 is at the infinite far away location.

We investigated the feasibility of the electropulse-driven inclusion removal from the molten steel. The experimental analysis shows that the electropulsing treatment is a promising method to remove the inclusions from the molten metal. Processing of clean steel by using the differences in electrical properties between inclusions and metals is different from any conventional methods based on the disparities in the density or size. Furthermore, electropulsing accelerates phase separation with less thermal energy compared with argonbubbling and electromagnetic-stirring-based clean steel processing methods. It should be noted that removal of MnS inclusions smaller than $20 \mu \mathrm{m}$ is usually very difficult by means of other conventional clean steel processing methods.

In conclusion, electropulsing enables the separation of the $\mathrm{MnS}$ inclusions from molten steel so as to lower the system free energy. The morphologies change from regular round or square to rod before and after electropulsing treatment, respectively. The MnS becomes large in size as a result of the enhanced aggregation driven by the passing electric current. Therefore, electropulsing treatment provides a special and effective approach to remove inclusions from molten steel to improve their mechanical, physical and corrosion resistance properties.

The work was financially supported by EPSRC (No. EP/J011460/1), TATA Steel and the Royal Academy of Engineering. The authors are grateful to Prof. Kenneth C Mills at Imperial 
College London for fruitful discussions and for Mr Christopher McDonald and Mr Andrew Smith at TATA Steel Teesside Technology Centre for provision of the steel samples.

\section{References}

[1] L. Zhang, B. G, Thomas, ISIJ Int. 43 (2003) 271.

[2] K. W. Lange, Inter. Material Reviews, 33 (1988) 53.

[3] E. Fuchs, P. Jonsson, High Temp. Mater. Process. 19 (2000) 333.

[4] P. Cremer, J. Driole, Metall. Trans. B 13 (1982) 45.

[5] D. Shu, B. D. Sun, J. Wang, T. X. Li, Y. H. Zhou, Metall. Mater. Trans. A 30 (1999) 2979.

[6] D. Apelian, R. Mutharasan, J. Met. 32 (1980) 14.

[7] S. Taniguchi, J. K. Brimacombe, ISIJ Int. 34 (1994) 722.

[8] L. Guan, G. Y. Tang, P. K. Chu, J. Mater. Res. 25 (2010) 1215.

[9] J. P. Barnak, A. F. Sprecher, H. Conrad, Scripta Metall. Mater. 32 (1995) 879.

[10] H. Conrad, Mater. Sci. Eng. A 287 (2000) 227.

[11] Y. Z. Zhou, R. S. Qin, S. H. Xiao, G. H. He, B. L. Zhou, J. Mater. Res. 15 (2000) 1056.

[12] X. L. Wang, J. D. Guo, Y. M. Wang, X. Y. Wu, B. Q. Wang, Appl. Phys. Lett. 89 (2006) 061910.

[13] R. S. Qin, E. I. Samuel, A. Bhowmik, J. Mater. Sci. 46 (2011) 2838.

[14] Y. Z. Zhou, W. Zhang, J. D. Guo, G. H. He, Philos. Mag. Lett. 84 (2004) 341.

[15] S. J. Zheng, Y. J. Wang, B. Zhang, Y. L. Zhu, C. Liu, P. Hu, X. L. Ma, Acta Mater. 58 (2010) 5070.

[16] I. Muto, Y. Izumiyama, N. Hara, J. Electrochem. Soc. 154 (2007) C439.

[17] R. S. Qin, B. L. Zhou, Int. J. Non-Equilib. Proc. 11 (1998) 77.

[18] R. S. Qin, S. X. Su, J. D. Guo, G. H. He, B. L. Zhou, Nanostruct. Mater. 10 (1998) 71. 
[19] W. Zhang, W. S. Zhao, D. X. Li, M. L. Sui, Appl. Phys. Lett. 84 (2004) 4872.

[20] H. Conrad, Mater. Sci. Eng. A 287 (2000) 205.

[21] M. Mach, P. Karban, I. Dolezel, D. Trutwin, 4th International Scientific ColloquiumModelling for Material Processing, Riga, June 8-9 (2006) 203.

[22] M. Danielewski, S. Mrowec, Solid State Ionics 17 (1985) 29. 